\title{
Realtime Monitoring Suhu Klem Jumper Pada Sistem Transmisi Tegangan Tinggi
}

\author{
Anak Agung Gde Ekayana \\ Program Studi Sistem Komputer \\ STMIK STIKOM Indonesia \\ Denpasar, Indonesia \\ ekayana888@gmail.com
}

\author{
I Wayan Teguh Wirapratama \\ Program Studi Sistem Komputer \\ STMIK STIKOM Indonesia \\ Denpasar, Indonesia \\ wirapratama@pln.co.id
}

\begin{abstract}
Abstrak-Pemantauan suhu klem jumper pada peralatan gardu induk maupun jumperan pada tower transmisi belum dilaksanakan secara optimal. Keterbatasan jam kerja karyawan membuat operator gardu tidak bisa memonitor kondisi suhu konektor selama 24 jam nonstop. Sering kali kenaikan suhu pada konektor terjadi diluar jam kerja yaitu terjadi saat beban puncak, malam hari atau hari libur.

Sistem monitoring suhu klem ini merupakan alat yang berfungsi untuk memonitor kondisi suhu konektor secara realtime 24 jam nonstop pada peralatan gardu induk maupun jumperan pada tower transmisi. Alat ini dikembangkan berbasiskan mikrokontroler Arduino Uno. Sensor suhu menggunakan sensor DS $18 S 20$ untuk memantau data suhu maupun proses pengiriman data. Alat ini menggunakan modul GSM SIM900 mampu mengirimkan data suhu konektor berbasis sms gateway dan mengirimkan data ke database.

Hasil pengujian alat ini mampu memberikan data suhu, yang dibaca oleh sensor DS $18 S 20$ dan mengirimkan data suhu dengan Modem GSM ke database berselang 5 Menit.
\end{abstract}

Katakunci-Arduino Uno; DS 18S20; modul GSM; database; suhu tegangan tinggi.

\section{PENDAHULUAN}

Perkembangan teknologi mikrokontroler dewasa ini, membuat proses otomatisasi suatu pekerjaan menjadi lebih mudah dan efisien. Dewasa ini perkembangan mikrokontroler seperti Arduino sangat banyak digunakan dalam pembuatan sistem kontrol atau otomatisasi suatu pekerjaan. Selain karena lebih mudah didapatkan di pasaran juga karena pemrogramannya yang lebih mudah dan banyak terdapat contoh-contoh penggunaan aplikasinya.

Fenomena hotspot atau titik panas banyak terjadi pada sistem transmisi tegangan tinggi. Hal ini terjadi karena adanya peningkatan dari nilai arus listrik maupun nilai tahanan. Pada sistem transmisi tegangan tinggi terjadi fluktuasi arus listrik sesuai dengan pola pemakaian tenaga listrik maupun akibat dari pengaturan sistem oleh dispatcher pengatur beban kelistrikan. Kenaikan nilai tahanan pada klem jumper maupun konektor turut mempengaruhi kenaikan suhu atau hospot pada konektor. Penyebab kenaikan nilai tahanan ini dipengaruhi oleh banyak hal seperti mur baut yang kendur, banyaknya polutan yang terjadi pada klem dan ketidaksesuaian ukuran konduktor dengan konektor. pemantauan suhu klem jumper maupun konektor pada sistem transmisi tegangan tinggi dilakukan menggunakan kamera citra termal atau Thermovision. Kamera ini dapat mendeteksi nilai suhu pada suatu benda pada jarak tertentu. Penggunaan kamera termal di PT. PLN
(Persero) sebagai perusahaan yang menyediakan tenaga listrik dilakukan oleh petugas pemeliharaan Gardu Induk selama jam kerja yaitu pada pukul 08.00 - 16.00 WITA pada hari senin - jumat, sehingga pemantauan suhu konektor atau jumper tidak dapat dilakukan setelah jam kerja selesai.

Dengan kejadian putusnya jumper konduktor pada Tower SUTT (Saluran Udara Tegangan Tinggi) Kabel Head - Gilimanuk yang terjadi pada hari minggu tanggal 26 April 2016 pukul 08.30 WITA yang merupakan di luar jam kerja memberikan kita gambaran bahwa kenaikan temperatur konektor atau jumper dapat terjadi kapan saja. Sehingga diperlukan sistem monitoring suhu jumper pada setiap titik konektor atau jumper yang dapat merekam perubahan suhu yang terjadi pada periode waktu tertentu dan memberikan informasi peringatan bila suhu melebihi dari yang ditentukan kepada petugas pemeliharaan PT. PLN (Persero). Solusi yang dapat diberikan dari permasalahan diatas adalah "Realtime Monitoring Suhu Klem Jumper Pada Sistem Transmisi Tegangan Tinggi.

\section{ANALISIS PERANCANGAN}

Sistem monitoring suhu klem jumper pada sistem transmisi adalah sistem yang bertujuan untuk memonitoring suhu klem jumper transmisi. Sistem ini akan memantau tingkat kenaikan suhu klem secara realtime dengan menggunakan sensor suhu Ds 18S20, apabila suhu melebihi 


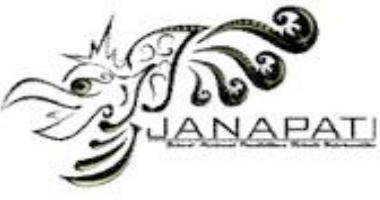

$50^{\circ} \mathrm{C}$, mikrokontroler akan mengirimkan sms ke Hp petugas pemeliharan.

Rancangan alat ini menitikberatkan pada pengukuran suhu klem jumper pada konduktor SUTT (Saluran Udara Tegangan Tinggi) atau pada klem konektor pada Switchyard Gardu Induk dengan menempelkan alat ukur ini pada baut klem jumper atau konektor yang bertegangan. Kemudian pembacaan nilai dari sensor suhu DS 18S20 dilakukan oleh mikrokontroler Arduino Uno. Data yang diperoleh tersebut diolah oleh mikrokontroler Arduino Uno sebelum dikirim melalui Modul GSM SIM900.

Rancang bangun yang dibuat menggunakan analisa resiko yang akan terjadi jika alat monitoring suhu jumper ini dipasang pada sistem transmisi tegangan tinggi antara lain:

1. Pengaruh medan listrik dan medan magnet.

2. Pengaruh temperatur atau suhu yang diukur dengan peralatan elektronik yang terdapat didalam alat ini.

3. Letak pemasangan alat yang berada di luar ruangan yang sangat dipengaruhi oleh cuaca.

Rancang bangun alat monitoring yang terdiri dari 2 lapisan yang berfungsi sebagai pelindung alat monitoring suhu ini terdapat pengaruh-pengaruh dari kondisi yang ada dilapangan. Yaitu pelindung luar yang terbuat dari bahan aluminium yang dilapisi oleh silikon agar tidak bocor dan berfungsi sebagai Sangkar Faraday yaitu pelindung peralatan dari pengaruh medan listrik yang dipengaruhi oleh arus listrik dan medan magnet yang dipengaruhi oleh tegangan listrik. Pelindung panas yang terdapat di dalam casing aluminium yang terbuat dari bahan busa tahan panas jenis polyurethane. Pelindung ini berfungsi sebagai pelindung peralatan elektronik dari pengaruh panas luar atau suhu klem jumper yang diukur, sehingga tetap dapat berfungsi maksimal saat terjadi panas berlebih. Alat monitoring suhu klem konektor ini berukuran panjang 100 $\mathrm{mm}$, lebar $75 \mathrm{~mm}$, tinggi $75 \mathrm{~mm}$ dan lubang tempat baut ukuran $19 \mathrm{~mm}$.

Berikut adalah rancangan alat yang akan dibuat ditampilkan pada Gambar 1.

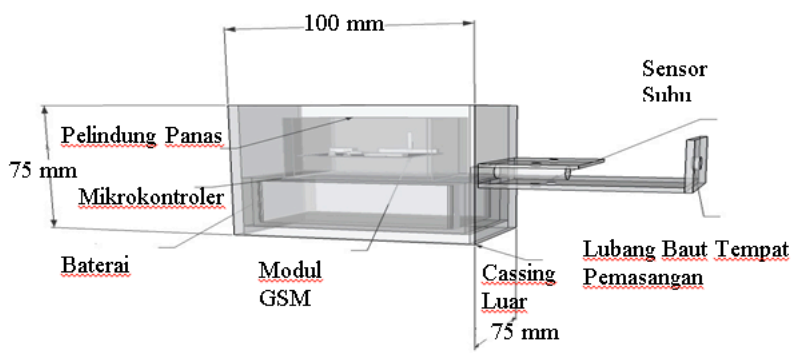

Gambar 1. Rancangan alat monitoring suhu jumper

Perangkat keras yang digunakan yaitu Sensor suhu jenis DS 18S20; kontroler yang digunakan adalah Arduino
p-ISSN 2089-8673 | e-ISSN 2548-4265

Jurnal Nasional Pendidikan Teknik Informatika (JANAPATI)

Volume 6, Nomor 1, Maret 2017

Uno yang menggunakan ATmega328; modul GSM yang digunakan adalah jenis SIM900.

Berikut ini adalah blok diagram alat monitoring suhu klem jumper ditampilkan pada Gambar 2.

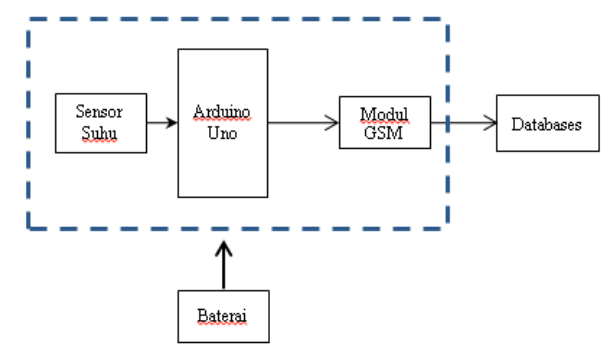

Gambar 2. Blok diagram alat monitoring suhu klem jumper

Pada Blok diagram yang ditunjukkan pada gambar 3 menunjukan sistem monitoring suhu klem jumper ini melibatkan Arduino Uno, sensor suhu, modul GSM SIM900 dan buzzer. Sensor suhu DS 18 s20 berfungsi mendeteksi suhu pada klem, kemudian hasil pembacaan dari sensor suhu tersebut diteruskan kepada mikrokontroler Arduino dan dikirimkan ke modul GSM pada satuan waktu tertentu dan apabila suhu melebihi suhu $60^{\circ}$ Celcius maka mikrokontroler akan memerintahkan modul GSM untuk menghidupkan alarm dan mengirim SMS kepada petugas pemeliharaan gardu induk.

Berikut ini rangkaian skematik alat monitoring suhu klem jumper yang terdiri dari mikrokontroler, port program, port modul GSM, port sensor suhu dan port buzzer yang ditampilkan pada Gambar 3.
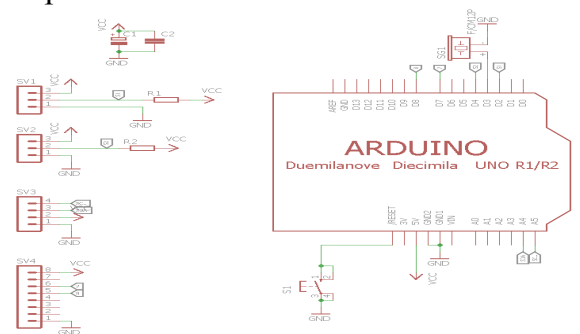

Gambar 3. Skematik Diagram alat monitoring suhu klem jumper

Agar pembuatan program menjadi lebih mudah, perlu dilakukan penggambaran secara grafik dari langkah langkah dan urutan prosedur dari suatu program. Maka dari itu pembuatan flowchart atau diagram alir sangatlah perlu dalam pembuatan program.

Berikut adalah penjelasan dari flowchart pemrograman pada Arduino dilakukan dengan membuat subrutin-subrutin sebagai berikut:

1. Mulai.

2. Inisialiasai port serial. 


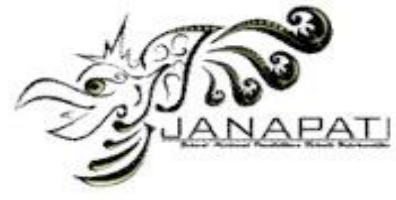

3. Pengambilan data dari sensor suhu.

4. Memasukkan nilai suhu ke database pada hosting.

5. Memilah nilai suhu yang melebihi suhu $60^{\circ}$ Celcius untuk dikirim sms melalui modul GSM SIM900.

6. Menerima dan mengirim SMS permintaan status suhu dan tegangan baterai saat itu.

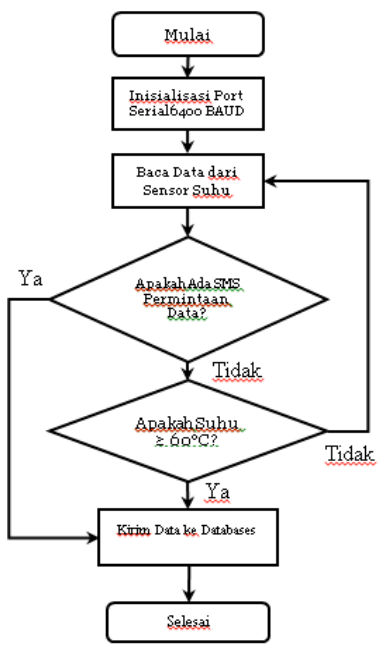

Gambar 4. Flowchart Alat monitoring suhu klem jumper

\section{HASIL DAN PEMBAHASAN}

Perancangan sistem monitoring suhu pada klem jumper sistem transmisi tegangan tinggi ini terdiri dari perancangan perangkat lunak maupun perangkat keras. Software ini akan ditulis menggunakan bahasa pemrograman $\mathrm{C}$ yang dibuat pada program Arduino IDE dan akan ditanamkan pada Arduino Uno. Untuk memasukkan program ke dalam Arduino Uno menggunakan kabel USB (Universal Serial Bus) tipe A-B Male.

Pertama adalah proses pembuatan cetakan casing luar yang terbuat dari besi. Pembuatan cetakan ini dibuat dari plat besi yang dipotong menggunakan gunting besi seperti ditunjukan pada Gambar 5.

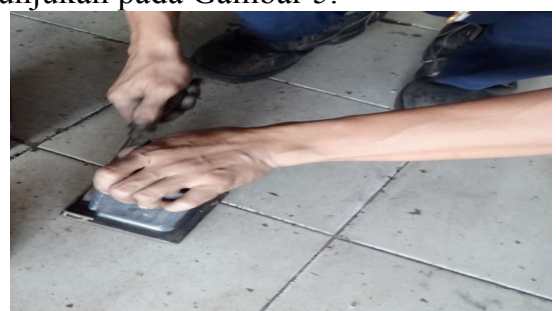

Gambar 5. Proses Mencetak Casing Aluminium

Pada Gambar 6 dibawah ini menunjukkan hasil cetakan besi yang sudah jadi, kemudian dilanjutkan dengan proses penuangan aluminium. Cetakan besi ini sudah diukur
p-ISSN 2089-8673 | e-ISSN 2548-4265

Jurnal Nasional Pendidikan Teknik Informatika (JANAPATI)

Volume 6, Nomor 1, Maret 2017

sesuai dengan ukuran casing luar yang memiliki ketebalan 10 milimeter.

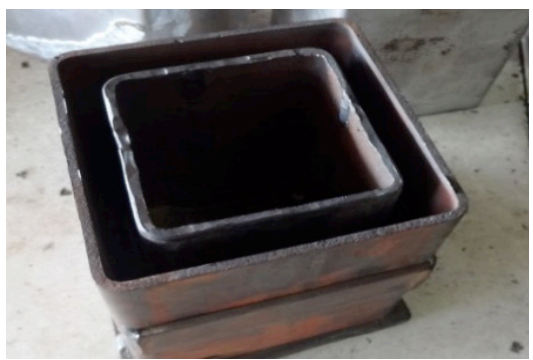

Gambar 6. Hasil Cetakan Besi yang Sudah Jadi

Kemudian dilanjutkan dengan proses menuangkan aluminium cair yang sudah dipanaskan terlebih dahulu ke dalam cetakan. Terlebih dahulu aluminium dipanaskan pada sebuah wajan hingga meleleh setelah mencapai suhu $660^{\circ}$ C. Setelah mencair, aluminium cair ini dituangkan ke dalam cetakan yang sudah dibuat terlebih dahulu.

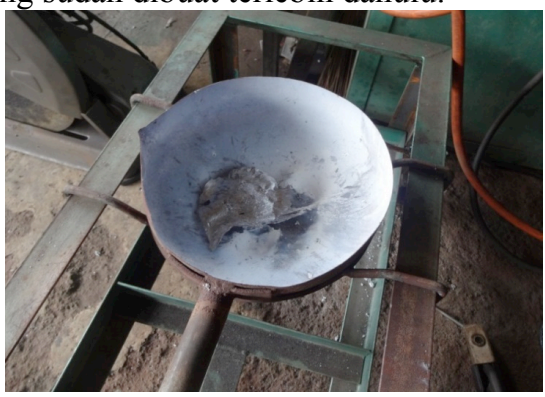

Gambar 7. Wajan Peleburan Aluminium

Kemudian aluminium cair dituangkan ke dalam cetakan, tunggu hingga aluminium mendingin dan mengeras sekitar 1 jam. Hasil cetakan setelah didinginkan tampak belum rapi dan rata seperti Gambar 8

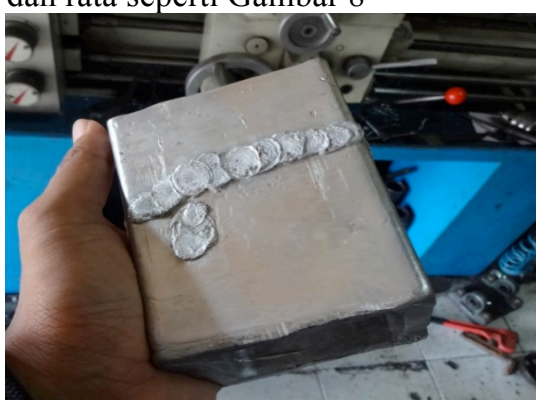

Gambar 8. Hasil Peleburan yang sudah didinginkan

Setelah casing aluminium didinginkan, dilanjutkan dengan proses merapikan dan pemberian lubang baut. Perapian menggunakan alat gerinda listrik, setelah casing rapi dilanjutkan dengan membuat lubang tempat baut penutup casing luar yang dipasang sebayak 8 buah setiap sisi. Pemasangan tempat baut ini bertujuan agar air tidak masuk ke dalam casing, seperti ditunjukan pada Gambar 9. 

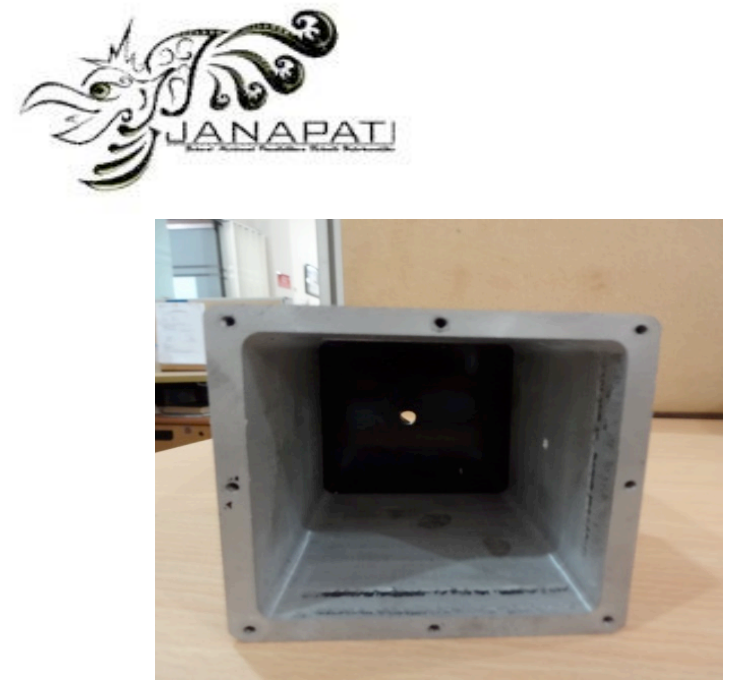

Gambar 9. Casing yang sudah dihaluskan

Kemudian dilanjutkan dengan membuat tutup casing luar yang terbuat dari plat besi dengan ketebalan 3 milimeter. Tutup casing ini dipasang pada dua sisi, dimana sisi yang menempel pada baut klem diberikan tambahan tempat untuk pemasangan baut seperti ditunjukan Gambar 10 .

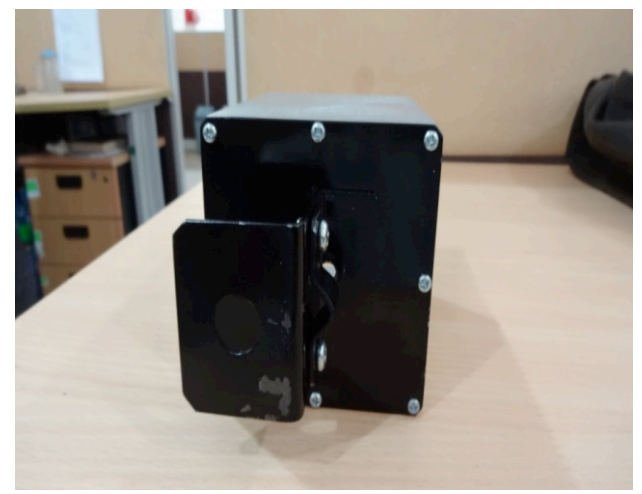

Gambar 10. Lubang tempat pemasangan alat monitoring

Tutup casing pada bagian yang menempel pada baut klem jumper tersebut juga diberikan tempat untuk pemasangan sensor suhu yang dikencangkan dengan dua buah mur baut. Seperti ditunjukan pada Gambar 11 dibawah ini.

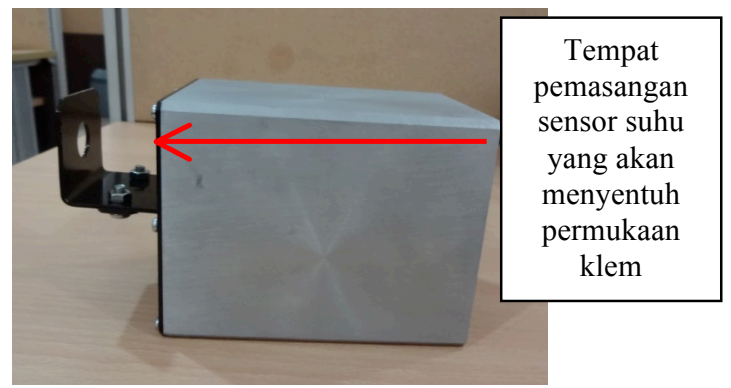

Gambar 11. Tampilan casing setelah dirapikan

Setelah selesai dalam pembuatan casing luar dilanjutkan dengan pembuatan casing dalam yang berbahan dari Acrylic yang berfungsi sebagai tempat komponen elektronik dan lapisan penahan panas polyurethane. Casing
p-ISSN 2089-8673 | e-ISSN 2548-4265

Jurnal Nasional Pendidikan Teknik Informatika (JANAPATI)

Volume 6, Nomor 1, Maret 2017

ini memiliki ukuran panjang $9 \mathrm{~cm}$, lebar $6,5 \mathrm{~cm}$ dan tinggi $6,5 \mathrm{~cm}$. Seperti ditunjukan pada Gambar 12.

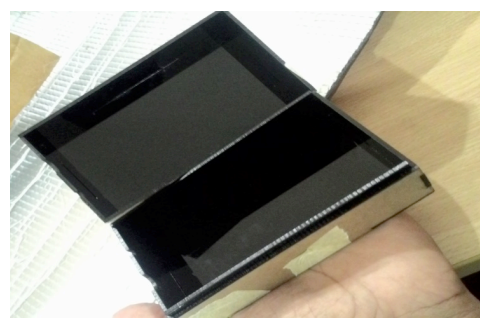

Gambar 12. Tampilan Casing Acrylic

Casing acrylic ini diberikan lubang untuk mengeluarkan kabel antena luar dan kabel sensor suhu. Lubang ini bertujuan agar kabel lebih mudah dikeluarkan ke posisi masing-masing, sehingga mencegah kerusakan kabel akibat tertekuk.

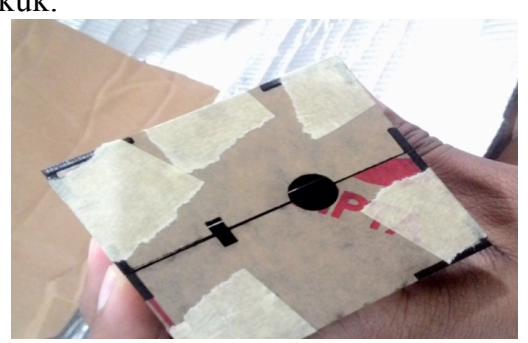

Gambar 13. Casing Acrylic yang digunakan

Kemudian dilanjutkan dengan proses pelapisan casing Acrylic menggunakan pelapis panas dengan bahan isolasi polyurethane yang ditunjukan pada Gambar 14, Pelapisan ini bertujuan untuk menpertahankan suhu komponen elektronik yang berada di dalam casing tetap terjaga dan tidak melebihi suhu normal komponen beroperasi.

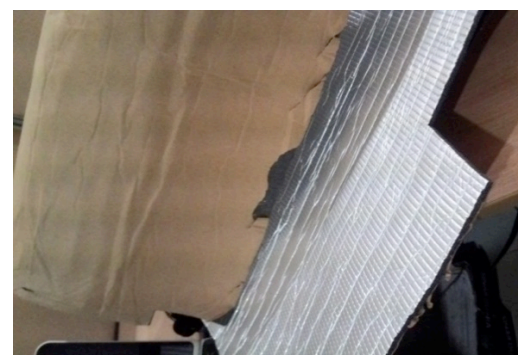

Gambar 14. Lembaran pelapis tahan panas

Casing acrylic dilapisi dengan bahan polyurethane yang memiliki ketebalan 5 milimeter. Pemasangan polyurethane ini dipasang menyeluruh pada setiap bagian casing acrylic. Lapisan ini dipotong pada sisi tengah agar mudah membuka casing acrylic tersebut. 

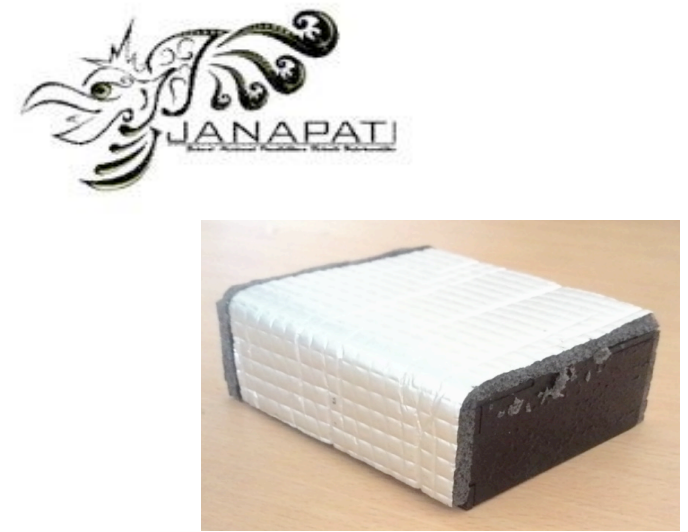

Gambar 15. Casing acrylic yang sudah dilapisi pelindung panas

Dalam proses pemasangan dan penempatan komponen meliputi proses pembuatan layout shield komponen, pemasangan komponen eletronika pada casing acrylic yang telah dilapisi penahan panas, pemasangan pada komponen ke dalam casing luar, dan hal-hal yang meliputi pembuatan rangkaian sistem, berikut ini tahap pembuatan instalasi jaringan elektronik

Pertama yang dilakukan adalah dengan membuat desain jalur rangkaian pada sebuah software yang bernama Eagle, yang kemudian desain tersebut diprint dan difotocopy pada plastik khusus, agar desain tersebut dapat ditempelkan nantinya pada papan PCB (Printed Circuit Board). Dalam penggambaran ini perlu diperhatikan bentuk dan ukuran dari masing-masing komponen yang akan dipasang terutama jarak antara kakinya. Berikut pada Gambar 16 dan Gambar 17 merupakan screenshot dari pembuatan jalur rangkaian pada Eagle.

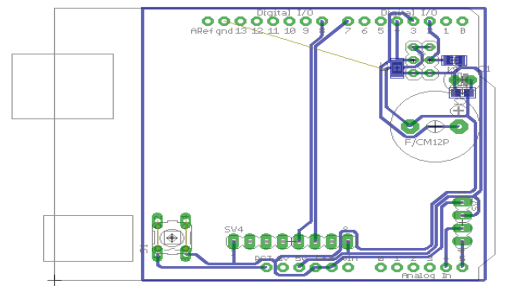

Gambar 16.Layout Peletakan Komponen Pada Arduino

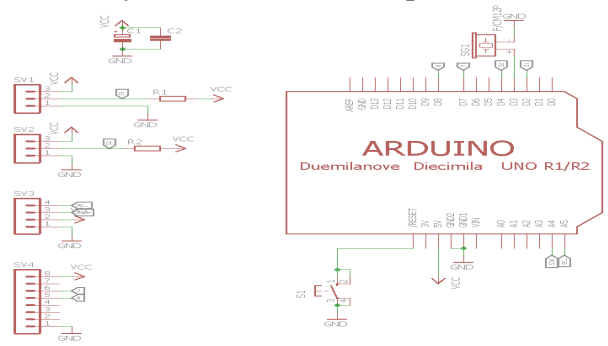

Gambar 17. Layout Pada Komponen Arduino

Proses perakitan komponen dengan menggabungkan semua komponen ke dalam casing yang sudah didesain sebelumnya. Komponen shield dipasangkan komponen yang terdiri dari modul GSM SIM900, Buzzer, Resistor, Female Conector pada shield tersebut, seperti ditunjukan pada Gambar 18.
p-ISSN 2089-8673 | e-ISSN 2548-4265

Jurnal Nasional Pendidikan Teknik Informatika (JANAPATI)

Volume 6, Nomor 1, Maret 2017

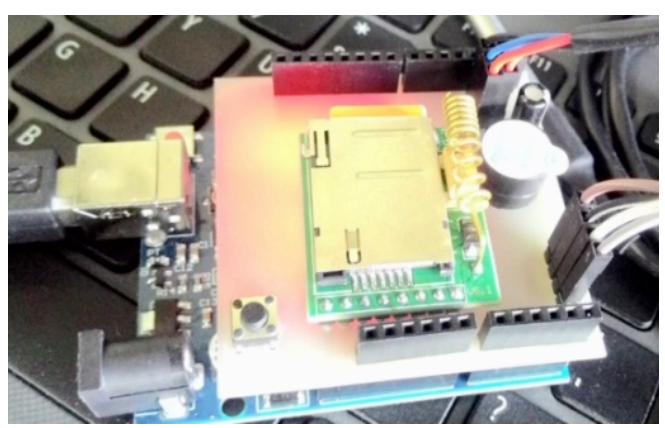

Gambar 18.Tampilan Shield pada Komponen Arduino

Setelah komponen-komponen shield dipasang, selanjutnya shield tersebut dipasang pada Arduino dengan cara menyolder komponen shield pada bagian female connector pin-pin pada Arduino.

Proses berikutnya adalah pengujian fungsi-fungsi alat sebelum dipasang pada peralatan bertegangan. Fungsi yang diuji antara lain tampilan nilai suhu sebelum dipanaskan, perubahan nilai suhu setelah dipanaskan dan proses pengiriman data ke database. Berikut adalah proses pengujian alat. Pertama adalah proses pengujian sebelum diberi panas yang berlebih. Sensor suhu akan membaca suhu lingkungan atau suhu benda yang disentuh oleh sensor suhu tersebut. Pada Gambar 19 dibawah ini penunjukan nilai suhu dari meja yang disentuh oleh masing-masing sensor suhu tersebut. Data suhu tersebut ditampilkan oleh layar LCD.

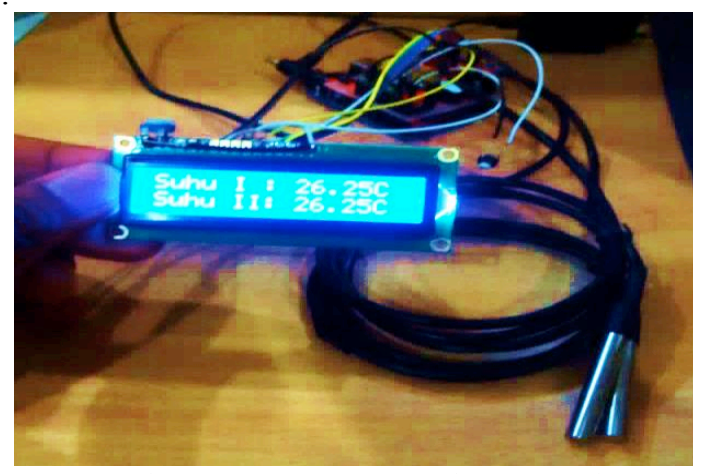

Gambar 19.Pengujian Pembacaan Suhu

\section{Proses Pembuatan Database}

Berikut adalah proses pembuatan database berbasis MySQL melalui aplikasi SQLyogEnterprise dan XAMPP. Database ini terdiri dari 1 tabel yang berisikan kolom-kolom isian seperti: no id alat, nama penghantar, no tower, line kabel, nama phasa, arah posisi klem, data suhu, tegangan baterai, status suhu, tanggal pengambilan data, waktu pengambilan data.

1. Pertama adalah melakukan koneksi ke database menggunakan aplikasi XAMPP seperti yang ditunjukan pada gambar 20 dibawah ini. Untuk melakukan koneksi 
ke database terlebih dahulu menekan tombol Start pada bagian Apache dan MySQL.

\begin{tabular}{|c|c|c|c|c|c|c|c|c|}
\hline \multicolumn{8}{|c|}{ 国 XAMPP Control Panel v3.1.0 3.1.0 [ Compiled: September 20th 2012 ] } & \multirow{2}{*}{$\begin{array}{r}\square \quad \times \\
\square \delta^{3} \text { Config }\end{array}$} \\
\hline 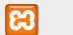 & \multicolumn{7}{|c|}{ XAMPP Control Panel v3.1.0 3.1.0 } & \\
\hline $\begin{array}{l}\text { Modules } \\
\text { Service }\end{array}$ & Module & PID(s) & Port(s) & Actions & & & & (2) Netstat \\
\hline$x$ & Apache & 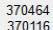 & 80,443 & Stop & Admin & Config & Logs & Da Shell \\
\hline$x$ & MySQL & 370492 & 3306 & Stop & Admin & Config & Logs & Explorer \\
\hline$x$ & Filezilla & 370568 & 21,14147 & Stop & Admin & Config & Logs & Services \\
\hline$\square$ & Mercury & & & Start & Admin & Config & Logs & (9) Help \\
\hline$x$ & Tomcat & & & Start & Admin & Config & Logs & Quit \\
\hline \multicolumn{2}{|c|}{$\begin{array}{l}15.17 .44 \text { [main] } \\
15.17 .44 \text { [main] } \\
15.174 \text { [Apache] } \\
15.17 .44 \text { [Apache] } \\
15.17 .4 \text { [mysall] } \\
15.17 .44 \text { [filezilla] } \\
15.17 .44 \text { [filezilla] }\end{array}$} & \multicolumn{6}{|c|}{ 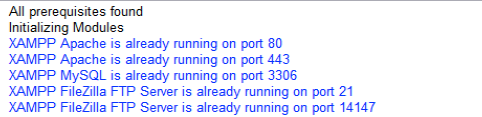 } & ^ \\
\hline
\end{tabular}

Gambar 20. Koneksi Database MySQL dengan XAMPP

2. Langkah selanjutnya adalah membuat nama database yang dibuat menggunakan aplikasi SQLyogEnterprise akan diberikan data suhu, yang ditunjukan pada Gambar 21

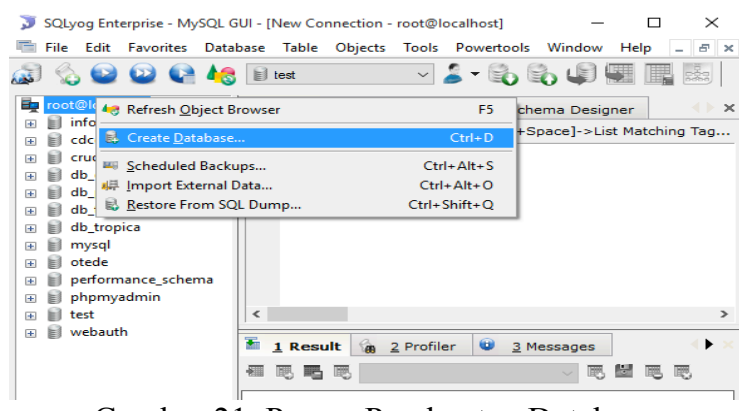

Gambar 21. Proses Pembuatan Database

3. Langkah selanjutnya adalah membuat nama tabel dan nama kolom yang diperlukan yang ditunjukan pada Gambar 22 dibawah ini. Dalam pembuatan nama kolom juga diisi tipe data, panjang data dan lain-lain. Kemudian database tersebut disimpan.

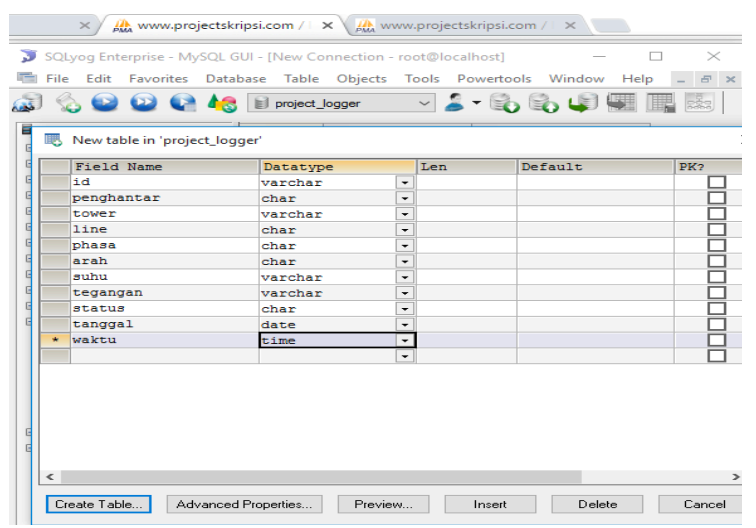

Gambar 22. Proses pembuatan kolom pada tabel
4. Kemudian dilanjutkan dengan proses memasukkan file database yang sudah dibuat sebelumnya ke database hosting dengan membuka cpanel hosting internet. Seperti pada Gambar 23 dibawah ini.

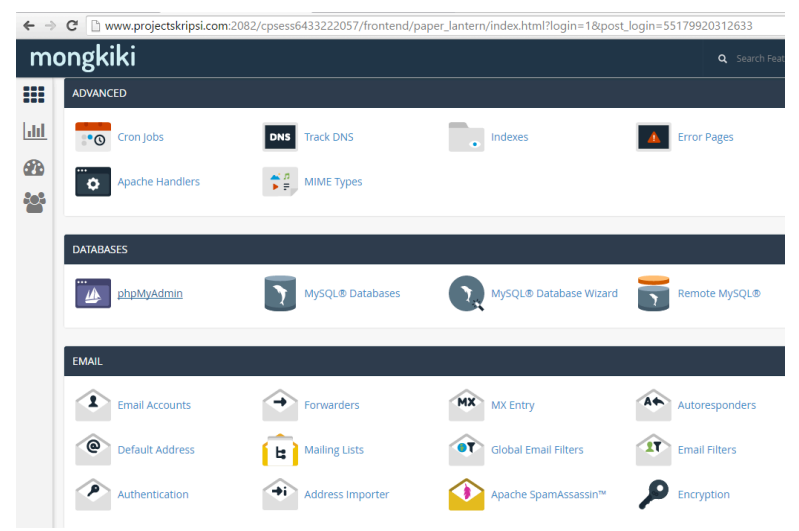

Gambar 23. Proses mengakases file CPanel Hosting

5. Langkah selanjutnya adalah membuka aplikasi PHPMyAdmin pada halaman CPanel hosting untuk memasukkan file SQL yang telah dibuat terlebih dahulu dari aplikasi SQLyogEnterprise dengan menekan tombol import dan memilih file sql yang diinginkan seperti yang ditunjukan pada Gambar 24 dibawah ini.

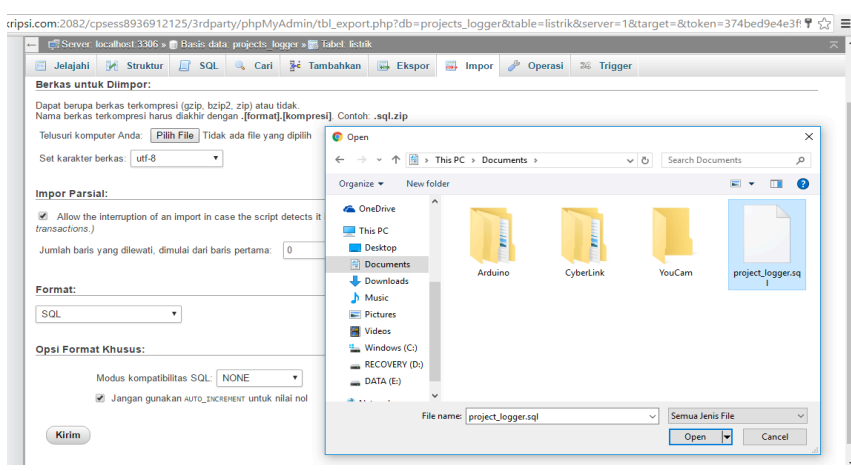

Gambar 24. Proses export file sql pada hosting

Setelah file sql di-import pada hosting, maka alat monitoring suhu sudah siap untuk mengirim dan menyimpan data suhu klem konektor.

Berikut adalah hasil dari pengujian pengririman data suhu melalui fungsi Modem GSM yang dilakukan setiap 5 menit sekali yang ditunjukan pada Gambar 25 dibawah ini. 

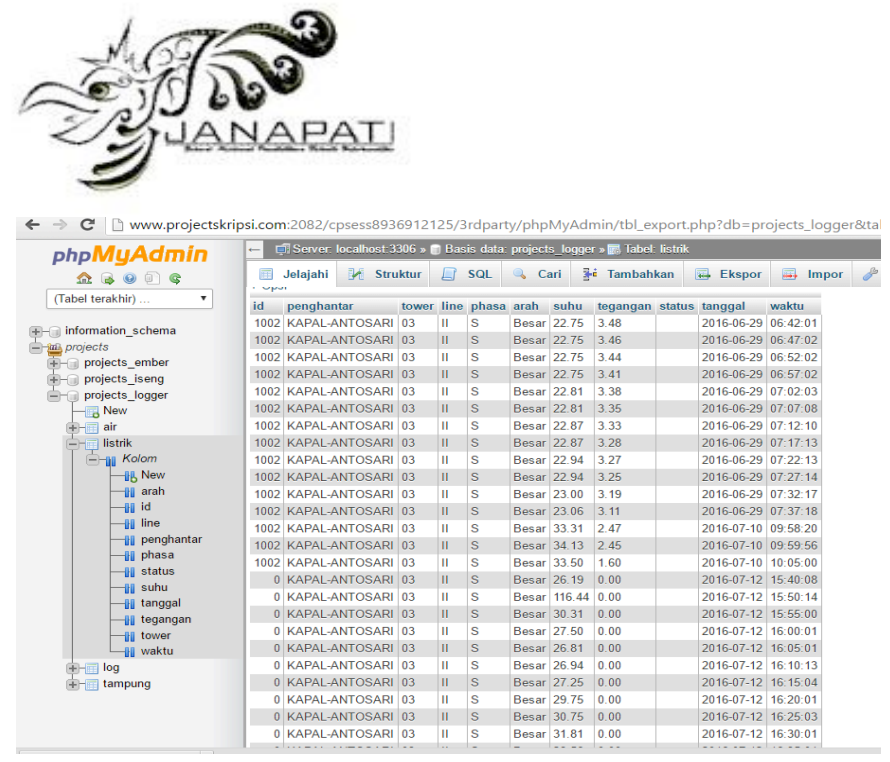

Gambar 25. Hasil Data yang Masuk ke Database setelah diberi Panas

\section{PENUTUP}

Dari hasil perancangan sistem dan pembuatan rancang bangun alat monitoring suhu klem jumper pada sistem transmisi dan setelah melakukan pengujian, maka dapat diambil kesimpulan dan saran.

Berdasarkan hasil penelitian yang di lakukan, dapat diambil kesimpulan, yaitu :

1. Rancang bangun sistem monitoring suhu klem jumper pada sistem transmisi tegangan tinggi menggunakan sensor suhu berbasis mikrokontroler Arduino Uno menggunakan modul GSM Sim900 sebagai media pengirim data suhu.

2. Unjuk kerja dari alat monitoring suhu klem jumper pada sistem transmisi dapat berfungsi dengan baik dalam pengukuran suhu klem dalam keadaan dialiri listrik bertegangan dengan menggunakan sensor suhu DS 18 s20 dan mikrokontroler dapat memproses pembacaan sensor sampai proses kirim data dengan menggunakan modul GSM sim900.

Berdasarkan dari hasil perancangan dan pembuatan rancang bangun alat monitoring suhu klem jumper pada sistem transmisi penulis menyampaikan saran yang berkaitan dengan perancangan ini yaitu :

1. Agar dikembangkan catu daya yang memiliki sumber daya listrik yang menggunakan induksi listrik sehingga kehandalan kerja alat ini menjadi lebih baik.

2. Kedepannya output dari alat monitoring ini dapat disingkronisasikan dengan website, sehingga dapat dipantau setiap kenaikan suhu pada suhu klem jumper.

\section{DAFTAR PUSTAKA}

[1] Artanto, D. 2012. Interaksi Arduino dan LabVIEW. Jakarta: Elex Media Komputindo.
p-ISSN 2089-8673 | e-ISSN 2548-4265

Jurnal Nasional Pendidikan Teknik Informatika (JANAPATI)

Volume 6, Nomor 1, Maret 2017

[2] Dickson, K. 2015. Pengertian Sensor Suhu dan JenisJenisnya.http: //teknikelektronika.com. Diakses pada tanggal 20 Maret 2016

[3] Kadir, Abdul. 2015. From Zero to A Pro: Arduino+CD.Yogyakarta: ANDI Offset

[4] PT. PLN (Persero), 2014. Buku Pedoman Pemeliharaan Saluran Udara Ekstra Tinggi (SUTT/SUTET). Jakarta. PT. PLN (Persero).

[5] PT. PLN (Persero), 2014. Buku Pedoman Pemeliharaan Serandang dan pentanahan GI. Jakarta. PT. PLN (Persero).

PT. PLN (Persero), 2008. Panduan Umum Pemeliharaan Transmisi TT/TET Dengan Metode PDKB. Jakarta. PT. PLN (Persero).

[6] Rohaeti Eli dan Suyanta.2011. Sintesis Busa Poliuretan Dari Minyak Jarak Sebagai Bahan Isolator Panas. http://staff.uny.ac.id/. Diakses pada tanggal 20 Maret 2016

[7] Sugianto, Azis. 2014.Purwarupa Sistem Pemantauan Kualitas Udara Secara Daring. http://www.academia.edu. Diakses pada tanggal 20 Maret 2016

[8] Triyono, Eddy.2015. Pemanfaatan Teralis sebagai Sangkar Faraday. http://jurnal.polines.ac.id/jurnal/index.php. Diakses pada tanggal 21 Maret 2016

[9] Widada. 2011. Pengertian Flowchart.doc. Gunadarma.ac.id. http://staff.gunadarma.ac.id. Diakses pada tanggal 15 Maret 2016 